\title{
IoT Arcade using Linux Embedded System
}

\author{
Jardeson de Araujo Arlindo \\ Computing Department Federal \\ Institute of Ceará Maracanaú \\ Campus, Brazil
}

\author{
Renata Imaculada Soares \\ Pereira \\ Electrical Engineering Department \\ Federal University of Ceará Pici \\ Campus, Brazil
}

\author{
Sandro César Silveira Jucá \\ Computing Department Federal \\ Institute of Ceará Maracanaú \\ Campus, Brazil
}

\begin{abstract}
This article describes a retro gaming central developed using Linux embedded system based on Raspberry Pi platform. The retro gaming center uses Internet of Things (IoT) principles to enabling monitor users' data. Thus, using minimum hardware and the free Linux operating system, the administrator can continuously optimize the project in low cost. The proposed system can be easily configured by beginners in electronics and computing, and also be applied as a didactic tool.
\end{abstract}

\section{General Terms}

Embedded systems, Internet of Things, Computing.

\section{Keywords}

Raspberry Pi, Arcade, Retro gaming.

\section{INTRODUCTION}

Technology for beginners in the areas of Computing and Electronics has always been a challenge [1]. Based on this principle, it is proposed a project where it is possible to arouse interest in electronics, programming and microcontrollers through the construction of an arcade-based software and free hardware for emulated digital games.

Retropie is free software that makes it possible to transform your Raspberry Pi into a large central game. Emulators in the system like Super Nintendo, Game Boy Advanced (GBA), Megadrive, Nintendo 64, among others. All this using the minimal configuration that the Linux embedded system based on Raspberry Pi can provide [2].

The Linux embedded system based on Raspberry Pi offers wide application, through which several related works have emerged, for example, the Wireless Monitor project [3], which is a free web application to receive and display data from IoT devices. Another project was developed using an RFID access control using the Internet principle of Things [4].

Thus, with the objective of developing the proposed arcade, it was necessary to research the basic principles of a game center (arcade) using simple materials, involving knowledge of Electronics and Computing. The proposed product was developed and installed in the Laboratory of Electronics and Embedded Systems (LAESE) at the Federal Institute of Ceará - IFCE, Maracanaú Campus (Brazil).

The Internet of things (IoT) principles were applied to obtain users data, such as, game frequency times, graph with hours of use during the day, amount purchased in the console; and data sending to the server, since a device for receiving coins has been installed and programmed. In the proposed product, the player must insert coins to receive credits and have access to the games.

\section{BIBLIOGRAPHIC REVIEW}

Game history begins with simple systems with no advanced interface, only bits on the screen [5]. Thus, the first video game was only possible with the use of an oscilloscope (electronic instrument for monitoring electrical signals in a cathode ray tube [6]), until the moment of arriving on TV's with the use of consoles, starting a series of accessories to be used as controls, $3 \mathrm{~d}$ glasses and guitars.

The initial concept of the games aimed to develop the logical reasoning in school activities, reported in research in the areas of computing and artificial intelligence. This research suffered a decrease in investments due to the high cost and high-power consumption of computers of the 1950s. The first electronic games were limited to tests and small demonstrations in 1951.

Due to the lack of documentation of these tests it is difficult to determine the first electronic game, but we can cite examples of "Nim" a mathematical game created by Chinese and "OXO" created by Alexander S. Douglas popularly known as "game of the old" [7].

\section{METHODOLOGY}

In this section, we describe the components and programs selected for the development of the arcade that is used by the IFCE students - Maracanaú Campus.

\subsection{Raspberry Pi}

The embedded computational system used for this product was Raspberry Pi (RPi) B +. The RPi is a complete low-cost minicomputer that has a CPU (Central Processor Unit), RAM (data), flash memory (program), GPIO (Input/Output) pins, enabling various IoT projects, residential automation, among others. All Raspberry Pi models use a MicroSD card as a hard drive for the OS (Operating System) and for file storage [8][10].

Raspberry Pi was initially created by the Trustee Foundation Eben Upton which brought together various teachers, academics and computer admirers to create a computer that would motivate children in Africa so they could learn programming and develop projects with simple, low cost hardware and easy access to various knowledge areas[11] [12].

\subsection{ESP8266}

The Esp8266 Microcontroller produced by the company Espressif Systems, obtained a great differential in the development of this product due to the low cost, and has a Wi-Fi embedded module. Several successful works have already been developed aiming at the use of this microcontroller that can be programmed using several programming languages, such as, the $\mathrm{C}$ language, Lua and MicroPython [10].

The Esp8266 NodeMCU is a development board that has a USB-serial interface and a $3.3 \mathrm{~V}$ voltage regulator. Programming can be done using communication via micro USB cable [13]. 


\subsection{Retropie}

Retropie is a free Linux-based software for Raspberry Pi that brings together several existing retro gaming projects in a single system, such as "Emulationstation" and "RetroArch", enabling the installation of several emulators, making it a lowcost easy-to-build console [2].

\subsection{Construction Of The Structure}

In this step, a paper mold was developed and later used for shaping the arcade wooden structure (Figure 1).

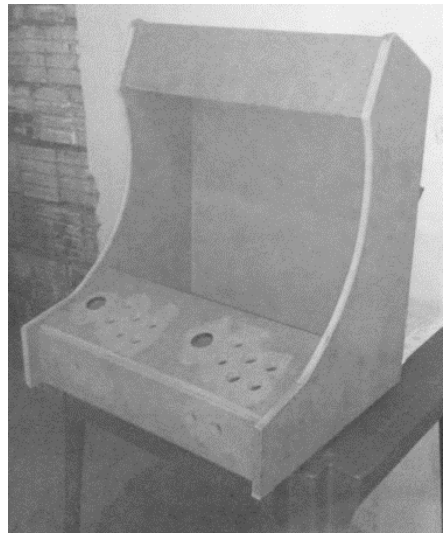

Fig 1: Construction of the wooden structure

For the wooden structure design, sufficient size to aggregate two players comfortably and for placing the monitor, buttons and speakers were considered [14]. The initial version of the constructed and painted arcade can be seen on Figure 2.

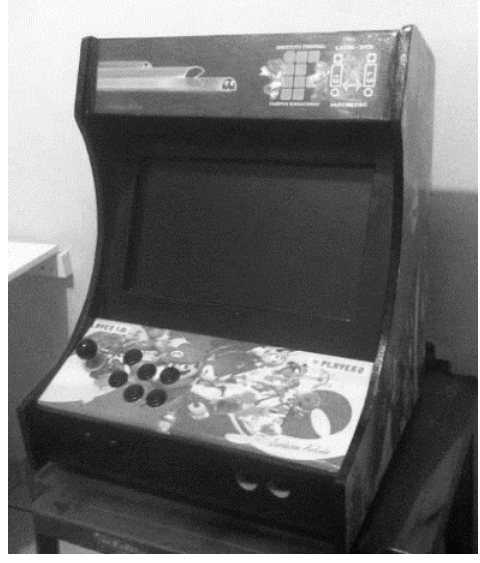

Fig 2: Initial version

We can observe on Figure 3 the button connections for user handling and electronic components mounted inside the structure. For each player six buttons and one control lever connected to a "Zero Delay" USB decoder are required. All the components are gathered by the "Zero Delay" board and issued via USB to the RPi. The data are interpreted by the Retropie program. Without using the "Zero Delay" board, connecting each button to a RPi GPIO pin and programming is necessary.

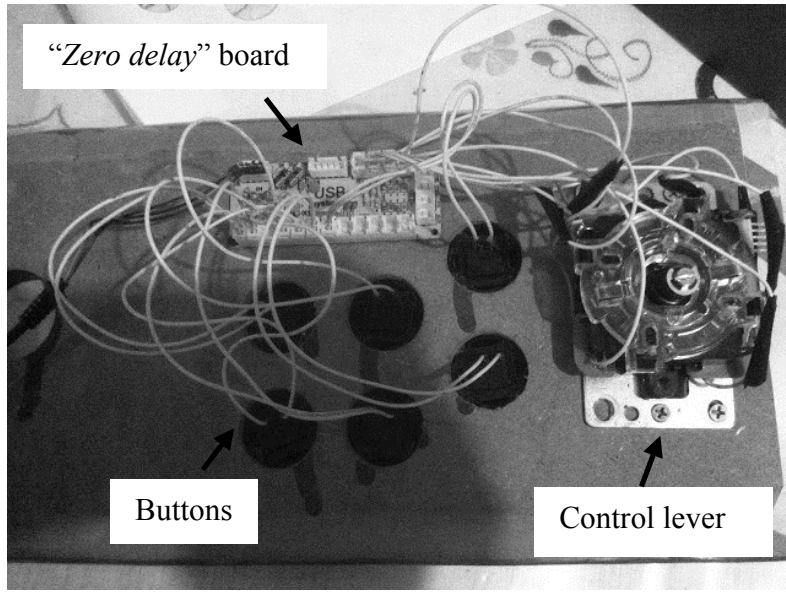

Fig 3: Control connections for one player

\subsection{Final Arcade Version}

According to Figure 4, which illustrates the proposed arcade product circuit, the Atx power source (1) feeds the entire circuit above (voltage $12 \mathrm{~V}$ ). In this system, the user inserts the coin into the coin-banker (2), which is a device in which the user inserts a standard sized coin $(25$ cents, 50 cents and one real (Brazilian currency)). If the user inserts a valid coin, the system will successfully start the game. If the coin is not in the accepted pattern, the coin-banker will not return the invalid coin and the game will not start.

The coin-banker sends an electronic pulse to the relay (3) connected to the input button (5), which, when triggered, sends this data to the "Zero Delay" board (4), which gathers all the buttons and sends the information via USB to the RPi (8). When triggered, the relay also sends the information to the Esp8266 (9) microcontroller that uploads this information to a server in the cloud (10).

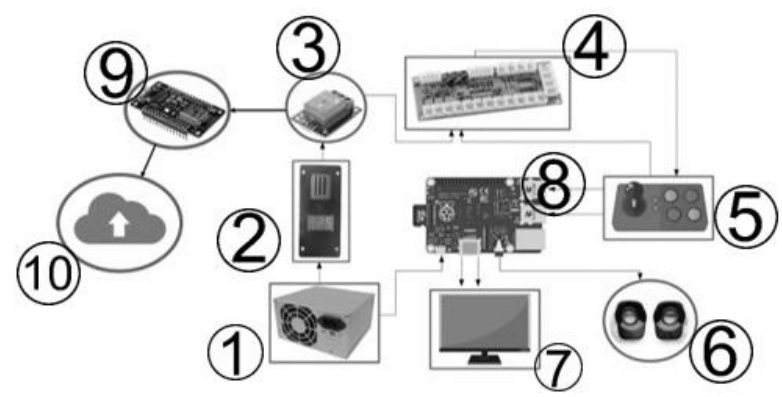

Fig 4: General schematic of the developed system

The signal that is received from the "Zero Delay" board is sent to the Raspberry Pi (8), to release the Controls (5) to the player. The entire system has audio speakers (6) and image (7) using a standard computer monitor. This arcade is also designed to work without paying. Thus, a button to add credits in the arcade without the need to insert coins was implemented. This function can be necessary for demonstration in schools or conferences, for example.

\subsection{Internet Of Things}

The Internet of Things (IoT) concept was created in the early 2000s by Kevin Ashton. The concept was simple: if we had computers that could capture all kinds of data without human intervention, we would be able to track and monitor everything via sensors, greatly increasing efficiency [15] [16]. 
The term IoT describes the large and ever-growing set of digital devices that operate between potentially global cloud networks. Among the applications are, for example, the capture of operational data from remote sensors on oil platforms, the collection of climate data and the control of intelligent thermostats [17].

In that sense, in the proposed retro gaming arcade, Esp8266 IoT module is used to account the coins inserted in the arcade and to send those data to a database in the cloud, thus constituting an example of an IoT application.

\section{RESULTS}

The final product with monitor, speakers, control buttons, coin-banker, Raspberry Pi and IoT microcontroller Esp8266 can be seen on Figure 5.

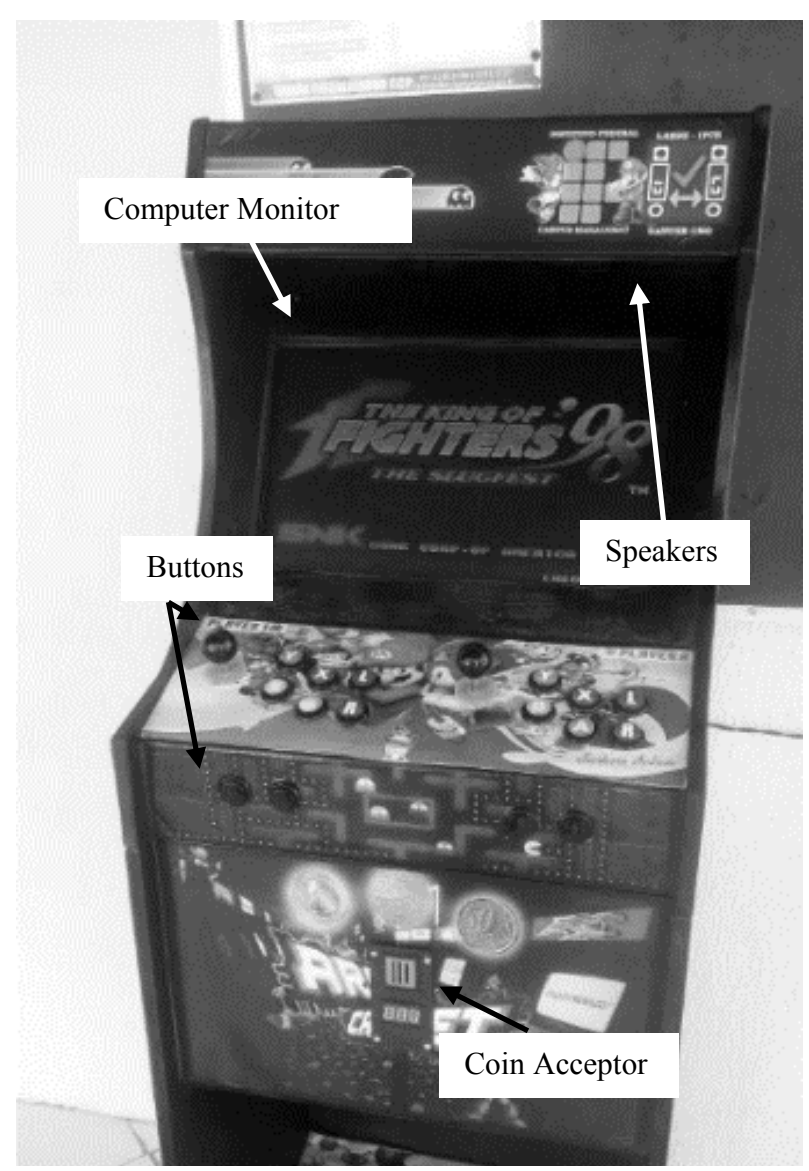

Fig 5: Final version of the retro gaming arcade developed

The Esp8266 receives the data obtained from the coins inserted in the arcade and sends them via embedded Wi-Fi module to the database that can be viewed by the PHPMyAdmin interface shown in Figure 6.

\begin{tabular}{|c|c|c|c|c|c|c|}
\hline & $\#$ & Nome & Tipo Agrupamento (Collation) & Atributos & Nulo & Predefinido \\
\hline$\square$ & 1 & Id & $\operatorname{int}(11)$ & & Não & None \\
\hline$\square$ & 2 & Data & date & & Não & None \\
\hline$\square$ & 3 & Hora & time & & Não & None \\
\hline$\square$ & 4 & Moedas & float & & Não & None \\
\hline
\end{tabular}

Fig 6: Database interface PHPMyAdmin

The graph of the Real (R\$) data obtained during the use of the arcade and time is collected and displayed on a Web page (Figure 7), using Google Charts (Google Graphs API) as monitoring. In this screen, the number of coins and the acquisition time are displayed, allowing the monitoring of any place.

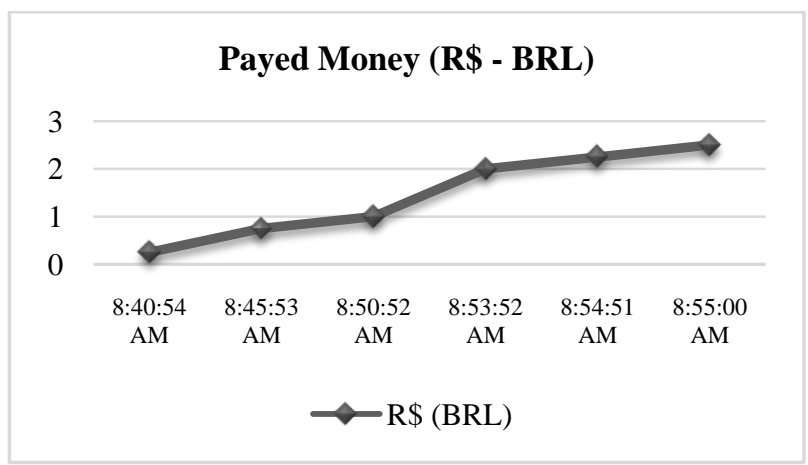

Fig 7: Online monitoring of coins obtained while using the arcade

Figure 8 shows a graph of the estimated total cost of the product developed with Raspberry Pi in relation to a computer and an Arcade system of 1980. Four Real (R\$) is equal to one Dollar (US\$) using quotation from July 2018.

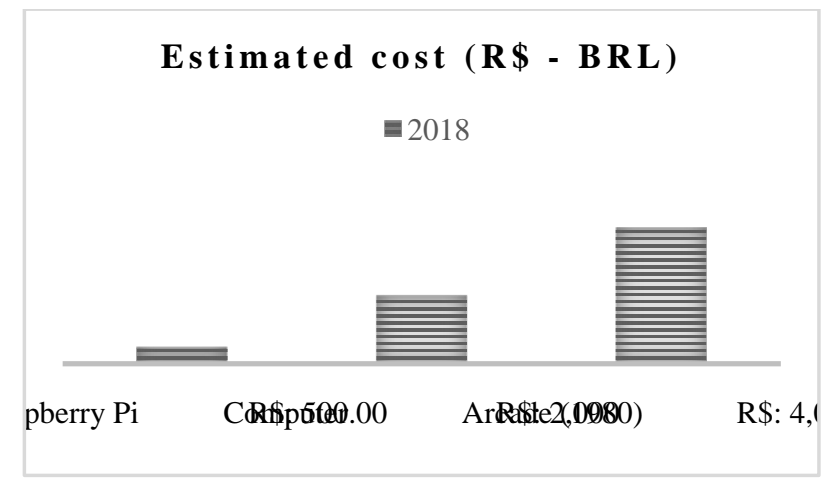

Fig 8: Comparison of total estimated cost between the product developed and commercial products

\section{FINAL CONSIDERATIONS}

During the development of this product, it was possible to observe that the practical implementation obtained satisfactory results. o Raspberry $\mathrm{Pi}$ has enough processing hardware to run the games. It was also verified that the developed system interface is totally friendly and intuitive for the end user. As a learning tool, it is possible to arouse interest in embedded systems, using a simple hardware and software system.

The possibility of adding Internet in an equipment as a form of monitoring is a factor of great importance for innovation projects, since the products can be monitored from anywhere, which also allows verification of use and data collection for modifications and optimizations of the system, characterizing an Internet of Things concept.

For future projects, it is interesting to use only one embedded system like Raspberry Pi 3, which can replace Raspberry Pi $\mathrm{B}+$ (game image processing) and Esp8266 (sends data to the Cloud). Raspberry Pi B+ has insufficient processing capacity, causing system slowness and game crashing.

By default, any Raspberry Pi enters standby mode after some minutes of inactivity, to reduce power consumption. By adding proximity infrared sensors, it is possible to detect if players are close to the arcade, thus allowing more efficient control of the power consumption. 


\section{REFERENCES}

[1] F. W. Scharpf, Games and simulation in higher education, $2^{\circ}$ ed., New York London, 2018.

[2] J. Wills, "RetroPie GitHub", 2017. [Online]. Available at: https://github.com/RetroPie/RetroPie-Setup/wiki. [Accessed: 11-mar-2018].

[3] A. Camurca e S. C. S. Juca, "Wireless Monitor - Free Web Application”, in ERIPI, 2017, p. 17-22.

[4] P. H. M. Araujo, R. P. Figueiredo, D. L. Dias, e S. C. S. Jucá, "RFID access control using the Internet of Things principle", in ERIPI, 2017, p. 61939-140.

[5] M. de L. S. Batista, P. L. Quintão, S. M. Lima, L. C. D. Campos, e T. J. de S. Batista, "A Study on the History of Electronic Games", Rev. Eletrônica da Fac. Metod. Granbery, p. 1-24, 2007.

[6] G. Aranha, "The consolidation process of videogames as instruments of communication and knowledge construction", Ciências \& Cognição, vol. 03, p. 21-62, 2004.

[7] Leonardo Tórtoro Pereira, "History of Electronic Games". ICMC-USP, p. 218, 2012.

[8] RaspberryPi Foundation, "Raspberry Pi Hardware Raspberry Pi Documentation”, 2016. [Online]. Available at:

https://www.raspberrypi.org/documentation/hardware/ras pberrypi/README.md. [Acessado: 08-mar-2018].
[9] S. Mala, "IOT Based Smart Public Distribution System", IJCA, p. 11-15, 2017.

[10] L. M. Joshi, "Research paper on IOT based Air and Sound Pollution Monitoring System", IJCA, vol. 178, no 7, p. 36-49, 2017.

[11] A. K. Kyaw, H. P. Truong, e J. Joseph, "Low-Cost Computing Using Raspberry Pi 2 Model B", vol. 13, no 3, p. 287-299, 2017.

[12] S. Bush, "Dongle computer lets kids discover programming on a TV", Electron. Wkly., maio 2011.

[13] E. Team, ESP8266 Technical Reference, $1^{\circ}$ ed. 2017.

[14] J. Palermo, T. Bussey, D. Gibson, e Gallagher, "Gaming machine with improved cabinet", 2017.

[15] M. Medina, "The Internet of Things", Eur. J. Commun., vol. 33, no 3, p. 344-346, 2018.

[16] H. Chen, X. Jia, e H. Li, "A brief introduction to IoT Gateway”, Proc. ICCTA, vol. 7, p. 5-8, 2011.

[17] M. Conti, A. Dehghantanha, K. Franke, e S. Watson, "Internet of Things security and forensics: Challenges and opportunities", Futur. Gener. Comput. Syst., vol. 78, p. 544-546, 2018. 